\title{
Erratum to: Early gastric adenocarcinoma arising within foveolar-type dysplasia in a patient with Muir-Torre variant Lynch syndrome
}

\author{
Tristan F. P. McKnight ${ }^{1} \cdot$ Amy E. Noffsinger ${ }^{2} \cdot$ Kara K. Landry $^{1} \cdot$ Ovais Ahmed $^{3}$ • \\ Rebecca Wilcox ${ }^{1}$
}

Published online: 15 June 2017

(C) Springer-Verlag GmbH Deutschland 2017

Erratum to: Virchows Arch

DOI 10.1007/s00428-017-2146-7

The author name Kara M. Klingman has been corrected as Kara K. Landry. Please see corrected name in the author group section above.

The original article was corrected.

The online version of the original article can be found at http://dx.doi.org/ $10.1007 / \mathrm{s} 00428-017-2146-7$

Tristan F. P. McKnight

McKnight.Tristan@gmail.com

1 Department of Pathology and Laboratory Medicine, University of Vermont Medical Center/University of Vermont College of Medicine, Burlington, VT, USA

2 Department of Gastrointestinal Pathology, Miraca Life Sciences, Irving, TX, USA

3 Department of Gastroenterology and Hepatology, University of Vermont Medical Center/University of Vermont College of Medicine, Burlington, VT, USA 